\title{
Predictors and prevention of diabetic cardiomyopathy
}

This article was published in the following Dove Press journal:

Diabetes, Metabolic Syndrome and Obesity:Targets and Therapy 10 April 2013

Number of times this article has been viewed

\section{Vishalakshi Chavali \\ Suresh C Tyagi \\ Paras K Mishra}

Department of Physiology and Biophysics, School of Medicine, University of Louisville, Louisville, Kentucky, USA
Correspondence: Paras Kumar Mishra Department of Physiology and Biophysics, School of Medicine, 500 S Preston Street, HSC-A Room 1216, University of Louisville, Louisville, KY 40202, USA

Tel +I 5028523627

Fax +I 5028526239

Email parasbhu2005@gmail.com
Abstract: Despite our cognizance that diabetes can enhance the chances of heart failure, causes multiorgan failure, and contributes to morbidity and mortality, it is rapidly increasing menace worldwide. Less attention has been paid to alert prediabetics through determining the comprehensive predictors of diabetic cardiomyopathy (DCM) and ameliorating DCM using novel approaches. DCM is recognized as asymptomatic progressing structural and functional remodeling in the heart of diabetics, in the absence of coronary atherosclerosis and hypertension. The three major stages of DCM are: (1) early stage, where cellular and metabolic changes occur without obvious systolic dysfunction; (2) middle stage, which is characterized by increased apoptosis, a slight increase in left ventricular size, and diastolic dysfunction and where ejection fraction (EF) is $<50 \%$; and (3) late stage, which is characterized by alteration in microvasculature compliance, an increase in left ventricular size, and a decrease in cardiac performance leading to heart failure. Recent investigations have revealed that DCM is multifactorial in nature and cellular, molecular, and metabolic perturbations predisposed and contributed to DCM. Differential expression of microRNA (miRNA), signaling molecules involved in glucose metabolism, hyperlipidemia, advanced glycogen end products, cardiac extracellular matrix remodeling, and alteration in survival and differentiation of resident cardiac stem cells are manifested in DCM. A sedentary lifestyle and high fat diet causes obesity and this leads to type 2 diabetes and DCM. However, exercise training improves insulin sensitivity, contractility of cardiomyocytes, and cardiac performance in type 2 diabetes. These findings provide new clues to diagnose and mitigate DCM. This review embodies developments in the field of DCM with the aim of elucidating the future perspectives of predictors and prevention of DCM.

Keywords: diabetes, obesity, exercise, heart failure, miRNA, oxidative stress

\section{Introduction}

Diabetes mellitus (DM) is a metabolic disorder with multiple etiology and is one of the leading causes of morbidity and mortality worldwide. ${ }^{1-3}$ The prevalence of DM is increasing at an alarming rate and is predicted to occur in approximately $5 \%$ of the global population by $2025 .{ }^{4,5}$ There are two major types of DM: (a) type 1 diabetes (T1D) which is caused by deficiency or absence of insulin due to destruction of pancreatic beta cells and (b) type 2 diabetes (T2D) which is characterized by insulin insensitivity or intolerance. T1D is prevalent in the young (also called juvenile diabetes) and T2D is prevalent in adults. ${ }^{6}$ However, the number of both T1D and T2D patients is expected to increase 3-4 fold by 2050 in the United States. ${ }^{7}$ The progression from prediabetes to diabetes has also contributed to the rapid increase in the number of people diagnosed with diabetes. It is estimated that nearly $5 \%-10 \%$ of the global population per year 
either progress to diabetes or improve reverting to normal glucose levels. However, the size of the prediabetic population is increasing worldwide and it is estimated that nearly 470 million people will have prediabetes by $2030 .^{8}$

DM is associated with both microvascular (including retinopathy, nephropathy, and neuropathy) and macrovascular (including cardiovascular diseases) complications. ${ }^{8-12}$ Clinical studies suggest that the incidence of heart failure is $2-4$ fold higher in diabetics when compared to nondiabetic patients. ${ }^{13,14}$ Diabetic cardiomyopathy (DCM) is described as the structural and functional changes in the myocardium that are associated with diabetes in the absence of ischemic heart diseases, hypertension, or other cardiac pathologies.,.$^{2,3,15-19}$ Although it has been four decades since DCM was described, the pathogenesis and underlying mechanisms of the disease are not completely understood. Glucose has been considered as the main driving force for the development of DCM, ${ }^{16}$ however, recent clinical trials (UK Prospective Diabetes Study 33[UKPDS33], the Action to Control Cardiovascular Risk in Diabetes [ACCORD], the Action in Diabetes and Vascular Disease [ADVANCE] and the Veterans' Administration Diabetes [VADT] ${ }^{20}$ have revealed no significant effect of intensive glycemic control on mortality and amelioration of cardiovascular events. ${ }^{17}$ Hence, there is a dire need to understand the detailed mechanisms and factors associated with DCM. Additionally, novel approaches such as stem cell therapy, and micro-RNA (miRNA) may be a promising therapeutic target, for the treatment of DCM. This article embodies a brief overview of DCM, its predictors and preventative measures (at different stages of disease), and future perspectives of therapy.

\section{DCM}

Early studies have demonstrated that coronary artery disease (CAD) is the primary cause of cardiac death in diabetics. ${ }^{19,21}$ However, this notion was challenged by findings that there was a modest increase in atherosclerotic disease in diabetics when compared with age- and sex-matched nondiabetic controls, ${ }^{22}$ and absence of narrowing of the lumen in the intramural vessels in diabetics. ${ }^{23}$ These findings were enigmatic until 1972 when DCM was identified as heart failure without any clear symptom of hypertension, CAD, or valvular disease. ${ }^{24}$ DCM was corroborated by examination of left ventricular function and coronary angiogram in uncomplicated adult diabetics with a family history, ${ }^{25}$ where a significant reduction of stroke volume index and an elevation in end-diastolic pressure were demonstrated in diabetics when compared with agematched controls. Although no difference in ejection fraction (EF) was recorded between diabetics and control, there was a significant increase in end-diastolic filling pressure to volume (indicator of end-diastolic wall stiffness) in diabetics. ${ }^{25}$ Based on these findings, DCM is defined as a distinct entity characterized by the presence of abnormal myocardial performance or structure in the absence of epicardial CAD, hypertension, and significant valvular disease. ${ }^{15,26}$ Due to the multifactorial nature of diabetes, there are perturbations at both the cellular and molecular levels that predispose the heart to pathological structural and functional remodeling. These alterations may contribute to DCM; however, the detailed mechanism is not completely understood. Cardiomyopathy can be classified into two types: (1) primary cardiomyopathy where the cardiomyopathy primarily affects the function of the heart and (2) secondary cardiomyopathy where cardiac performance is affected due to a systemic syndrome. ${ }^{27}$ Cardiomyopathy leads to heart failure which can be either systolic heart failure with reduced EF or diastolic heart failure with normal $\mathrm{EF}^{28}$ The definition of DCM has been extended to DCM with normal EF and DCM with reduced EF, and includes all associated diabetic diseases affecting central hemodynamics. ${ }^{16}$

\section{Risk factors for DCM}

As diabetes is associated with DCM, elevated glucose level seems to be the major risk factor. ${ }^{16}$ However, the risk factors that contribute to diabetes or heart failure are also associated with DCM. These risk factors include a high fat diet/obesity, cardiovascular autonomic neuropathy (CAN), inflammation and elevated levels of free fatty acid (FFA), advanced glycation end products (AGEs) and their receptors, and reactive oxygen species (ROS). Recently, differential expression of miRNAs ${ }^{29,30}$ and stem cell survival and differentiation ${ }^{31}$ was associated with DCM (Figure 1).

\section{Mechanism underlying DCM}

The disturbances in metabolism that lead to hyperlipidemia, insulin insensitivity causing hyperinsulinemia, and deficiency of insulin due to pancreatic beta cell death causing hyperglycemia, contribute to DCM. ${ }^{3}$ The metabolic disturbances is mainly due to an elevation in nonesterified fatty acids, also called free fatty acid (FFA).,2,16 The heart has the potential to utilize both FFA and carbohydrate as a source of energy. However, the dominant source of energy is FFA, and this switches to carbohydrate with increased workload or starvation. ${ }^{32}$ The switch from FFA to carbohydrate may be due to fetal gene reprogramming. ${ }^{33}$ In the heart of diabetics, energy production by glucose utilization may be decreased and FFA utilization is increased and this causes depletion of glucose transporter (GLUT)-1 and $-4 .{ }^{34}$ The transgenic expression of GLUT-4 in diabetic mice restored cardiac metabolism and function, and this suggested that glucose metabolism 




Figure I Different risk factors associated with diabetic cardiomyopathy. Note: "^" indicates increased levels.

Abbreviations: AGE, advanced glycation end product; DCM, diabetic cardiomyopathy; FFA, free fatty acid; miRNA, micro-RNA; RAGE, receptor for AGE; ROS, reactive oxygen species.

was associated with DCM. ${ }^{35}$ The elevated level of FFA is implicated in cellular insulin resistance ${ }^{3,16}$ One mechanism by which FFA induces insulin resistance is through the protein kinase C (PKC) pathway. PKC (a serine/threonine kinase) phosphorylates inhibitor of kappa light polypeptide gene enhancers B- cells (IkKB) kinase, and this in turn phosphorylates insulin receptor substrate-1 (IRS-1). Phosphorylation of IRS- 1 inhibits its ability to bind to the $\mathrm{p} 85$ regulatory subunit of phosphatidylinositol 3-kinase, impairing insulin signal transduction in skeletal muscle. ${ }^{36}$ However, this signaling cascade is not demonstrated in the diabetic heart. Another mechanism of FFA-mediated insulin resistance is via peroxisome proliferator-activated receptor (PPAR)- $\gamma$. The activation of PPAR- $\gamma$ is associated with increased FFA that in turn induces the expression of phosphatase and tensin homolog deleted on chromosome 10 (PTEN). PTEN dephosphorylates phosphatidylinositol-3, 4, 5-triphosphate and this prevents activation of Akt (serine/threonine kinase)-1.,37 Increased levels of insulin induces cardiac hypertrophy by inhibiting glycogen synthase kinase- $3 \beta$, which inhibits nuclear transcription of the hypertrophic program through nuclear factor in activated lymphocytes. ${ }^{38,39}$ Elevated levels of insulin also upregulates Akt-1 and this induces mammalian target of rapamycin (mTOR) that in turn activates the $\mathrm{p} 70$ ribosomal subunit S6 kinase-1 and promotes protein synthesis contributing to cardiac hypertrophy. ${ }^{40-42}$

Peroxisome proliferator-activated receptor (PPAR- $\alpha$ ) is also activated by FFA and its activation induces pyruvate dehydrogenase kinase- 4 causing glucose oxidation and stimulating fatty acid uptake in the mitochondria. Along with an increase in long chain acyl carnitines, it promotes mitochondrial uncoupling of oxidative phospohorylation. ${ }^{43}$ Mitochondrial uncoupling of oxidative phosphorylation results in decreased myocardial high energy reserves and contractile dysfunction. ${ }^{19}$ The elevated level of FFA abrogates pyruvate dehydrogenase and this induces accumulation of glycolytic intermediates and ceramides, which may promote apoptosis. ${ }^{44,45}$ The lipotoxicity due to toxic metabolites from FFA opens K-ATP channels ${ }^{46}$ and this impairs the ability of cardiomyocytes to regulate calcium use, causing contractile dysfunction. ${ }^{47-49}$ The induction of apoptosis, hypertrophy, and contractile dysfunction leads to DCM (Figure 2A).

Hyperglycemia also triggers $\operatorname{ROS}^{50-52}$ by inducing glucose oxidation and generating mitochondrial superoxide..$^{52-55}$ ROS activates matrix metalloproteinases 9 (MMP9) which degrades extracellular matrix, increases matrix turnover, attenuates sarco-endoplasmic reticulum-calcium ATPase 2 (SERCA2), and alters the expression of several miRNAs that leads to contractile dysfunction and ultimately DCM. ${ }^{31,55,56}$ In diabetes, induction of MMP9 also increases inflammation by inducing pro-inflammatory tumor necrosis factor (TNF)- $\alpha$ and mitigating the anti-inflammatory interleukin (IL)-10 cytokine (unpublished data, 2013) which exacerbates DCM. ${ }^{55-60}$ Differential expression of several miRNAs also induces TNF- $\alpha$, inhibits IL-10, and regulates inflammation. ${ }^{61-63}$ Several miRNAs (such as miR-155 and miR-223) are anti-inflammatory and cardioprotective. ${ }^{64,65}$ Diabetesmediated generation of superoxide also causes DNA damage that triggers the reparative enzyme poly (ADP ribose) polymerase (PARP). ${ }^{50}$ The induction of PARP attenuates glyceraldehyde phosphate dehydrogenase and this diverts glucose from the glycolytic pathway into alternative pathways such as advanced glycation end products (AGEs) and the PKC pathway which downregulates the calcium regulating receptor and enzyme ryanodine receptor and SERCA2 respectively, impairing the contractility of cardiomyocytes, and inducing the ventricular stiffness that leads to DCM (Figure 2B). ${ }^{66-72}$

Diabetes cardiovascular autonomic neuropathy is manifested in both T1D and T2D, and is diagnosed with abnormal variation in diurnal and nocturnal blood pressure, resting heart rate disorder, exercise intolerance, and prolongation of QT interval in ECG. ${ }^{72}$ The attenuations of beta-1 and -2 adrenergic receptors (which are part of sympathetic tone) is also associated with DCM. ${ }^{74-77}$ The alterations in myocardial autonomic neurotransmitters cause toxic effects on catecholamines and apoptosis $^{19}$ which contributes to DCM. The microenvironment (oxidative stress, myocardial stiffness, differential expression of miRNAs) of the myocardium is changed in 


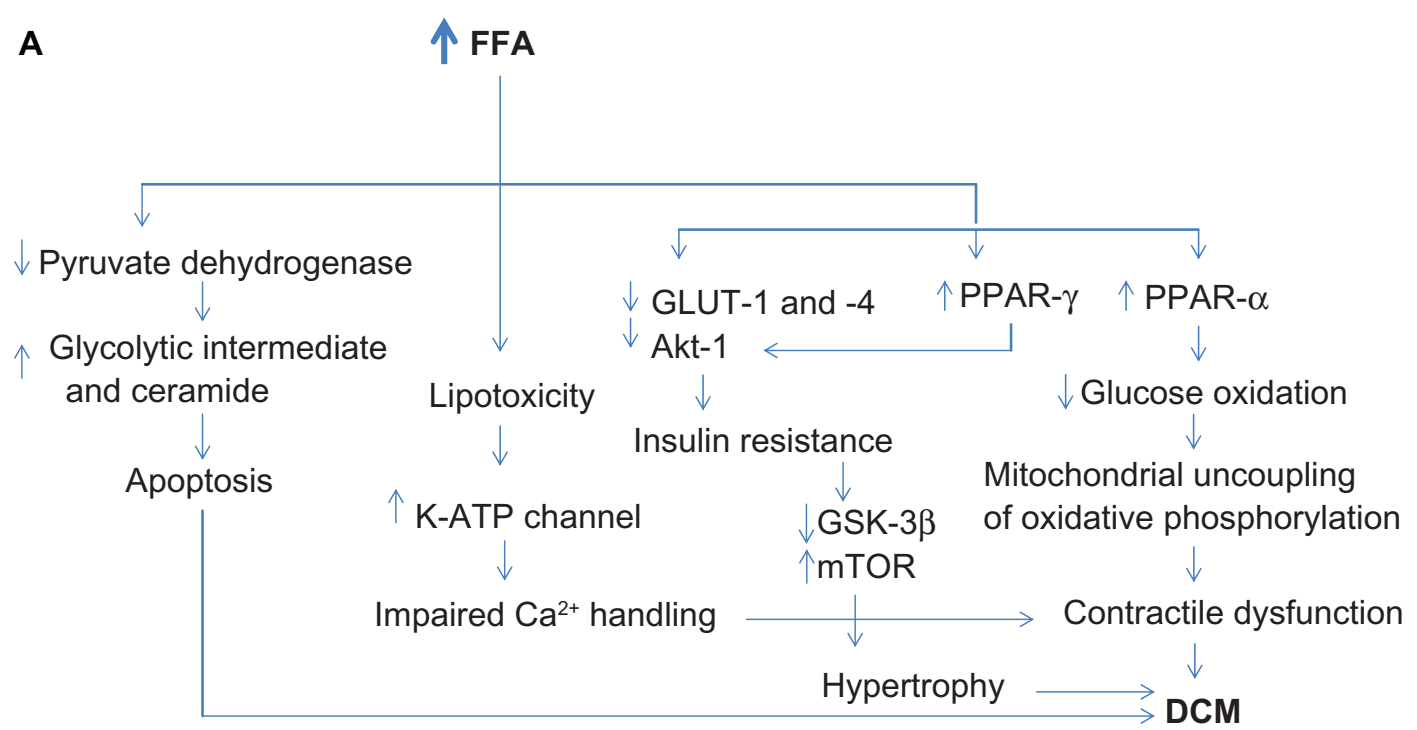

B Hyperglycemia

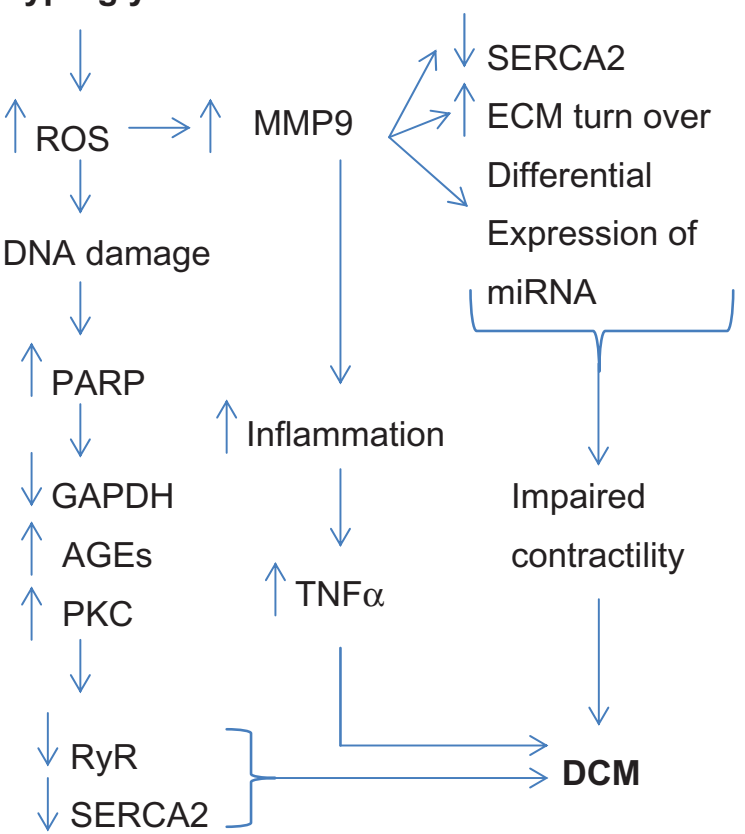

Figure 2 (A) Different pathways associated with increased free fatty acid mediated diabetic cardiomyopathy and (B) different pathways associated with hyperglycemia mediated diabetic cardiomyopathy.

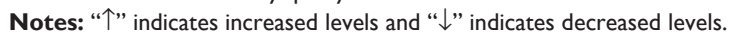

Abbreviations: AGE, advanced glycation end product; AKT-I, serine/threonine kinase; DCM, diabetic cardiomyopathy; ECM, extracellular matrix; FFA, free fatty acid;

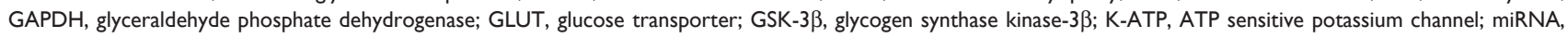
micro-RNA; MMP9, matrix metalloprotinease 9; mTOR, mammalian target of rapamycin; PARP, poly(ADP ribose) polymerase; PKC, protein kinase C; PPAR, peroxisome proliferator-activated receptor; ROS, reactive oxygen species; RyR, ryanodine receptor; SERCA2, sarco-endoplasmic reticulum-calcium ATPase 2; TNF- $\alpha$, tumor necrosis factor- $\alpha$.

the heart of diabetics, and this is implicated in defective cardiac progenitor cell growth and differentiation, ${ }^{16,31}$ which contributes to DCM.

\section{Pathophysiology and remodeling in DCM}

The high fat diet/obesity is associated with insulin resistance, T1D and T2D. In T2D, high blood glucose levels trigger pancreatic beta cells to release insulin; however, due to insulin insensitivity, glucose levels remain high. These hyperglycemic signals continuously activate beta cells to release insulin leading to hyperinsulinemia. The beta cells, due to their continued workload, die and thus, in the longterm, T2D leads to T1D (Figure 3). Diabetes is associated with structural (fibrosis, ${ }^{55,78}$ apoptosis, ${ }^{55,79,80}$ angiopathy ${ }^{81-83}$ ), functional (endothelium-myocytes uncoupling, ${ }^{55}$ impaired 


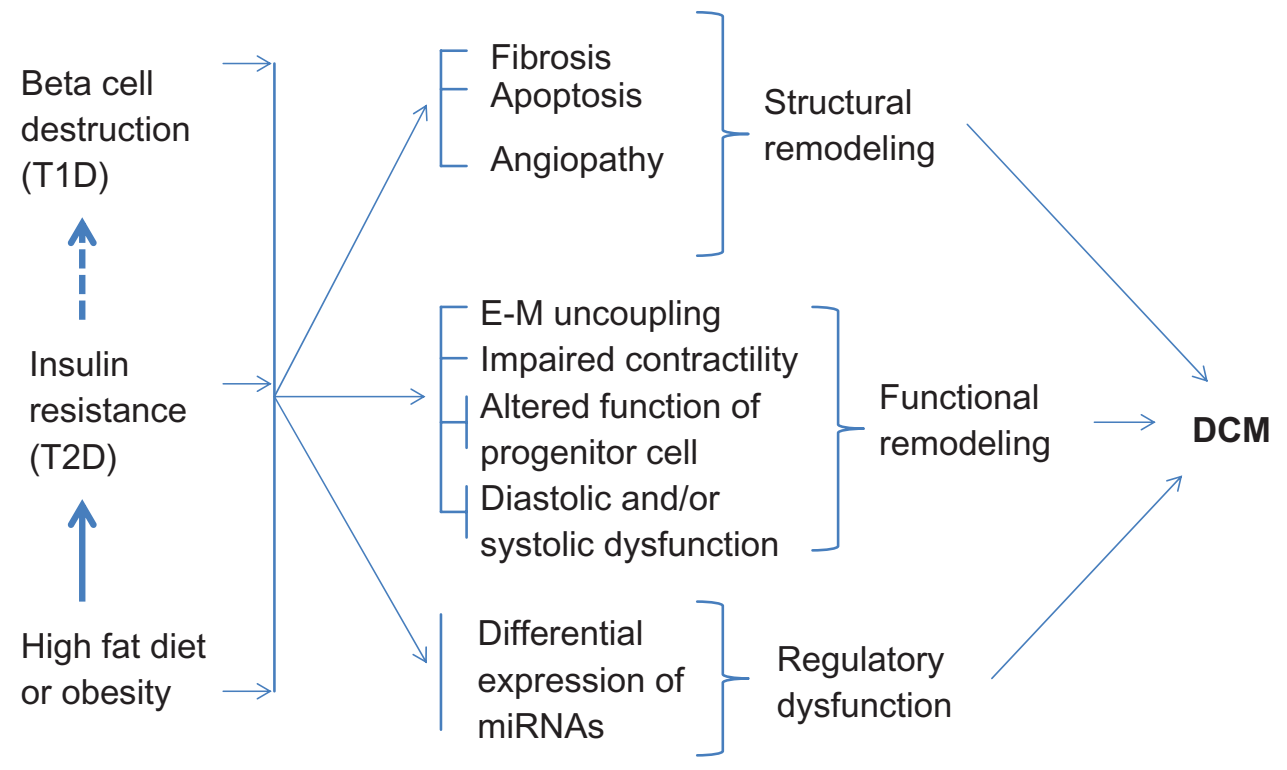

Figure 3 Effect of high fat diet, type I diabetes, and type 2 diabetes on cardiac remodeling leading to diabetic cardiomyopathy. Abbreviations: DCM, diabetic cardiomyopathy; E-M, endothelial-myocytes; TID, type I diabetes; T2D, type 2 diabetes.

contractility of cardiomyocytes, ${ }^{75}$ decreased survival and differentiation of cardiac stem cells, ${ }^{31}$ diastolic and systolic dysfunction $^{55,75,84,85}$ ), and regulatory (alteration in the levels of miRNAs ${ }^{29,30,86}$ and signaling molecules involved in glucose metabolism ${ }^{2,3,16,87}$ ) remodeling that leads to DCM (Figure 3).

There are three major stages of DCM: early stage, middle stage, and late stage. The early stage is asymptomatic, where the heart becomes hypertrophic and has diastolic dysfunction with normal EF. ${ }^{88}$ However, at the molecular level, increased levels of FFA, altered calcium homeostasis, and depletion of GLUT-1 and -4 are evident. ${ }^{2,16,34,89}$ The middle stage is recognized by increased left ventricle (LV) size, wall thickness, and mass, which is accompanied by diastolic dysfunction and a slight decrease in systolic function ( $\mathrm{EF}<50 \%)$. It is also accompanied by insulin resistance, AGE formation, increased levels of renin-angiotensin-aldosterone system (RAAS) and tumor growth factor- $\beta 1$, reduced levels of insulin growth factor-1, apoptosis, necrosis, fibrosis, and mild CAN. ${ }^{2,16,17}$ The progression from middle stage to late stage disease is associated with additional severities including microvascular changes, CAD, and CAN, which impairs both systolic and diastolic functions (Table 1). ${ }^{2,16,17}$

\section{Predictors and prevention of DCM}

The alarming increase in the number of diabetic patients with cardiomyopathy warrants the implementation of diagnostic strategies for DCM to identify the disease at its early stages. Currently, there is no well recognized method for early diagnosis of DCM. DCM induces changes in the heart structure (myocardial hypertrophy, fibrosis, and fat droplet deposition) and early changes in cardiac function are evident by the abnormal diastolic function that progresses to systolic dysfunction in the later stage of disease. These changes in patients with DCM can be diagnosed using the following methods:

Table I The phenotype and functional impairment in different stages of diabetic cardiomyopathy

\begin{tabular}{|c|c|c|c|}
\hline Stage & $\begin{array}{l}\text { Cellular } \\
\text { mechanism }\end{array}$ & $\begin{array}{l}\text { Structural } \\
\text { change }\end{array}$ & $\begin{array}{l}\text { Functional } \\
\text { change }\end{array}$ \\
\hline Early & $\begin{array}{l}\text { Increased FFA; } \\
\text { altered } \mathrm{Ca}^{2+} \\
\text { homeostasis; } \\
\text { depleted GLUT-I } \\
\text { and GLUT-4 }\end{array}$ & $\begin{array}{l}\text { Slightly increased } \\
\text { LV size, wall } \\
\text { thickness, and } \\
\text { mass }\end{array}$ & $\begin{array}{l}\text { Possible diastolic } \\
\text { dysfunction, } \\
\text { normal ejection } \\
\text { fraction }\end{array}$ \\
\hline Middle & $\begin{array}{l}\text { Insulin resistance; } \\
\text { AGE formation; } \\
\text { increased RAAS } \\
\text { and TGF- } \beta \text { I; } \\
\text { reduced IGF-I; } \\
\text { apoptosis; } \\
\text { necrosis; fibrosis; } \\
\text { mild CAN }\end{array}$ & $\begin{array}{l}\text { Increased LV size, } \\
\text { wall thickness, and } \\
\text { mass, dilatation, } \\
\text { fibrosis }\end{array}$ & $\begin{array}{l}\text { Diastolic } \\
\text { dysfunction, } \\
\text { ejection fraction } \\
\text { is }<50 \%\end{array}$ \\
\hline Late & $\begin{array}{l}\text { Hypertension; } \\
\text { microvascular } \\
\text { changes; } \\
\text { severe CAN; } \\
\text { CAD }\end{array}$ & $\begin{array}{l}\text { Increased LV size, } \\
\text { wall thickness, and } \\
\text { mass, dilatation, } \\
\text { fibrosis, micro- } \\
\text { angiopathy }\end{array}$ & $\begin{array}{l}\text { Systolic and } \\
\text { diastolic } \\
\text { dysfunction }\end{array}$ \\
\hline
\end{tabular}

Abbreviations: AGE, advanced glycation end product; CAN, cardiovascular autonomic neuropathy; CAD, coronary artery disease; FFA, free fatty acid; GLUT, glucose transporter; IGF-I, insulin growth factor-I; TGF- $\beta$ I, transforming growth factor- $\beta$ I; LV, left ventricle; RAAS, renin-angiotensin-aldosterone system. 
1. Echocardiography and Doppler imaging: In the early stage of DCM and in the majority (75\%) of asymptomatic diabetic patients, diastolic dysfunction characterized with heart failure with normal EF is present. ${ }^{88}$ Diastolic dysfunction, mitral inflow patterns, mitral $\mathrm{E} / \mathrm{E}^{\prime}$, transmitral $\mathrm{E} / \mathrm{A}$, cardiac stiffness, and dilatation of the LV can be assessed by echocardiography..$^{16,90-92}$ Therefore, echocardiography and Doppler imaging can be utilized to evaluate structural and functional remodeling in the heart of diabetics. However, numerous factors such as myocardial fibrosis, hypertrophy, and contractile asynchrony changes in calcium cycling are involved in altering the normal LV diastolic function. ${ }^{90}$ These changes are not confined to DCM but are also present in other cardiac diseases, ${ }^{15,91}$ and therefore, other approaches are required for diagnosing DCM.

2. Magnetic resonance imaging (MRI): MRI is a highly sensitive tool for detecting LV wall motion abnormalities, geometry, and cardiac hypertrophy. ${ }^{91,93-95}$ MRI is considered to be a favorable tool for the accurate measurement of LV mass, volume, and function. ${ }^{96-99}$. Additionally, it provides information on arrhythmia and cardiomyopathy. ${ }^{100}$

3. Serological biomarkers:

a. High levels of glucose and hemoglobin $\mathrm{A}_{1 \mathrm{c}}$ are indicators of diabetes.

b. Increased levels of $\mathrm{N}$-terminal pro-brain natriuretic peptide and brain natriuretic peptide are markers of heart failure.

c. Troponin present in the plasma, is an indicator of necrosis.

d. Elevated level of MMPs (especially MMP9) and decreased levels of tissue inhibitor of metalloproteinases (TIMPs) are indicators of fibrosis. ${ }^{16}$

e. Levels of the enzyme beta O-GlcNAc (o-linked $\mathrm{N}$-acetylglucosamine) can also be used as a predictor of DCM as it is increased in hypertrophy and cardiovascular diseases. ${ }^{101-103}$

4. Heart catheterization and coronary angiography: Different stages of DCM can be diagnosed by left heart catheterization that assesses LV end diastolic pressure and right heart catheterization that measures mean pulmonary wedge pressure which is often associated with increases in mean pulmonary pressure. ${ }^{16}$ Coronary angiography determines stenosis in the coronary artery which is often present in late stages of DCM. ${ }^{15}$

\section{MiRNA as a potential biomarker for DCM}

MiRNA are small ( 22 nucleotide), conserved, non-coding RNA molecules that modulate gene expression either through
mRNA degradation or translational repression. ${ }^{104}$ They are emerging as promising therapeutic targets for cardiovascular disease and diabetes. ${ }^{29,30}$ The levels of miRNAs are altered in the hearts of diabetics. ${ }^{105,106}$ Recently, circulating miRNAs were reported as biomarkers for cardiovascular disease. ${ }^{107-116}$ Therefore, the differential expression of specific circulating miRNAs can be used to diagnose different stages of DCM (Table 2).

\section{Prevention of DCM}

Although tight regulation of glucose levels is thought to ameliorate DCM, recent clinical trials (UKPDS 33, ACCORD, ADVANCE, and VADT $)^{21}$ have failed to support this. ${ }^{17}$ Based on the different stages of DCM, different preventative measures should be taken.

Early stage DCM: Changes in lifestyle and diet are the measurable factors that prevent DCM progression and may even cure the disease. A low fat and glucose diet, and physical exercise can mitigate early DCM.

Middle stage DCM: In addition to exercise and diet control, treatment with metformin for T2D, insulin for T1D, pioglitazone for ameliorating diastolic dysfunction, and betablockers for reducing blood pressure may be required.

Late stage DCM: In addition to the above mentioned preventative measures for middle stage DCM, angioplasty is required to mitigate micro- and macro-angiopathy and for coronary stenosis (Table 2).

\section{Antidiabetic drugs for treatment of DCM}

Metformin (one of the most commonly prescribed drugs) improves peripheral sensitivity to insulin, promotes hyperglycemic control, and acts as an anti-inflammatory agent. ${ }^{92,117,118}$ Glucagon-like peptide (GLP)-1 is an incretin hormone that stimulates postprandial insulin secretion and improves insulin sensitivity. Individuals treated with GLP-1 also have improved left ventricular ejection fraction. ${ }^{92}$

\section{Other classes of drugs for treatment of DCM}

The trials with statins and RAAS inhibitors also show positive results for mitigating DCM. ${ }^{91,92,119-125}$ Statins inhibit cholesterol biosynthesis, and have anti-inflammatory and anti-oxidative stress functions. They also improve LV function and reduce fibrosis that ameliorates DCM..$^{92,119-125}$ RAAS inhibitors are also cardioprotective. Angiotensin-converting enzyme inhibitors and angiotensin receptor blockers are commonly used to block the RAAS. Results based on clinical and experimental studies suggest that RAAS inhibitors not only reduce 
Table 2 Predictors of and preventative measures for diabetic cardiomyopathy

\begin{tabular}{|c|c|}
\hline Predictors & Preventative measures \\
\hline I. Serological markers & Early DCM \\
\hline a. Increased levels of $\mathrm{N}$-terminal pro-brain natriuretic & Lifestyle modification \\
\hline peptide (NT proBNP) & a. Exercise \\
\hline b. Increased levels of BNP & b. Controlled diet (less glucose) \\
\hline c. Hyperglycemia & Middle DCM \\
\hline d. Elevated $\left.\mathrm{Hb}_{\mathrm{Ic}}\right\}$ Diabetes & I. Lifestyle modification \\
\hline e. Troponins infrequent or positive necrosis & a. Exercise \\
\hline f. Elevated MMPs (especially MMP9) & b. Diet with less glucose \\
\hline g. Decreased TIMPs $\}$ Fibrosis & 2. Treatments \\
\hline h. Altered levels of circulating miRNAs & a. Metformin (T2D) \\
\hline 2. Morphology & b. Insulin (TID) \\
\hline a. Hypertrophy & c. Pioglitazone (mitigates diastolic dysfunction) \\
\hline b. Dilatation & d. Beta-blocker (decreases hypertension) \\
\hline c. Micro- and macro-angiopathy & Late DCM \\
\hline 3. Echocardiography & 3. Lifestyle modification \\
\hline a. Mitral valve $E / E^{\prime}$ & a. Exercise \\
\hline b. Transmitral E/A ratio & b. Diet with less glucose \\
\hline c. \% fractional shortening & 4. Treatments \\
\hline 4. Magnetic resonance imaging & a. Metformin (T2D) \\
\hline a. LV mass, volume and function & b. Insulin (TID) \\
\hline b. Systolic and diastolic dysfunction & c. Pioglitazone (mitigates diastolic dysfunction) \\
\hline 5. Heart catherisation & d. Beta-blocker (decreases hypertension) \\
\hline a. $\mathrm{LV}$ end diastolic pressure $(>15 \mathrm{mmHg})$ & e. Angioplasty (for microangiopathy and coronary stenosis \\
\hline b. Mean pulmonary wedge pressure $(>15 \mathrm{mmHg})$ & f. miRNA treatment? \\
\hline $\begin{array}{l}\text { 6. Coronary angiography } \\
\text { a. Coronary artery stenosis: micro-angiopathy }\end{array}$ & g. Stem cell therapy? \\
\hline
\end{tabular}

Abbreviations: BNP, B-type natriuretic peptide; DCM, diabetic cardiomyopathy; $E / E^{\prime}$, ratio between mitral peak velocity of early filling (E) to early diastolic mitral annular velocity ( $\left.E^{\prime}\right)$; E/A, ratio between early $(E)$ and late (atrial - A) ventricular filling velocity; $\mathrm{Hb}_{\mathrm{lc}}$, glycosylated haemoglobin; $\mathrm{LV}$, left ventricle; miRNA, micro-RNA; MMP, matrix metalloproteinase; TIMP, tissue inhibitor of metalloproteinase; TID, type I diabetes; T2D, type 2 diabetes.

blood pressure but also help to improve insulin sensitivity and enhance blood glucose uptake. Diastolic dysfunction is ameliorated by RAAS inhibitor treatment. ${ }^{91}$ The use of betablockers in diabetic patients is not common considering different parameters such as blood glucose, insulin resistance, and dyslipidemia; however, recent meta-analyses suggest that the use of these beta-blockers improves glycemic levels and insulin resistance when compared with other antidiabetic drugs. ${ }^{91}$

\section{Conclusions and future directions}

Several hypotheses have been proposed to describe how DCM develops, ${ }^{3,16}$ however, DCM is still a valid challenge in medical science as the number of diabetics in the population is rapidly increasing. Although recent trials have revealed that tight glucose regulation is not as effective as first thought, control of hyperglycemia is essential to mitigate DCM. It is clear that DCM is regulated not only by high glucose levels; there are several other factors and mechanisms (Figures 1-3) that contribute to DCM. The role of high blood pressure, hyperlipidemia, and oxidative stress also contributes to, and exacerbates, DCM. Early diagnosis is essential for preventing and reverting DCM. For early diagnosis, serological markers, echocardiography, and MRI are important. Recent advances in the areas of miRNA and stem cell therapy provide a new dimension to explore DCM and its therapy. The levels of specific miRNA during early, middle, and late stage DCM can be used as a biomarker for different stages of DCM. The use of miRNA mimics and antagomiR (if a miRNA is attenuated and up regulated, respectively) can be exploited to mitigate DCM. Similarly, stem cells can be used for regenerating pancreatic beta cells and myocardium to improve glucose metabolism and cardiac function, respectively.

\section{Acknowledgement}

This work is supported in part by the American Heart Association grant 11BGIA 7690055 and National Institute of Health grants HL-113281 (P.K.M.), HL-108621 (SCT) and HL-74185 (SCT).

\section{Disclosure}

The authors report no conflicts of interest in this work.

\section{References}

1. Ashcroft FM, Rorsman P. Diabetes mellitus and the beta cell: the last ten years. Cell. 2012;148(6):1160-1171.

2. Goyal BR, Mehta AA. Diabetic cardiomyopathy: pathophysiological mechanisms and cardiac dysfunction. Hum Exp Toxicol. Epub November 22, 2012. 
3. Poornima IG, Parikh P, Shannon RP. Diabetic cardiomyopathy: the search for a unifying hypothesis. Circ Res. 2006;98(5):596-605.

4. King H, Aubert RE, Herman WH. Global burden of diabetes, 1995-2025: prevalence, numerical estimates, and projections. Diabetes Care. 1998;21(9):1414-1431.

5. Wild S, Roglic G, Green A, Sicree R, King H. Global prevalence of diabetes: estimates for the year 2000 and projections for 2030. Diabetes Care. 2004;27(5):1047-1053.

6. Mishra PK, Singh SR, Joshua IG, Tyagi SC. Stem cells as a therapeutic target for diabetes. Front Biosci. 2010;15:461-477.

7. Centers for Disease Control and Prevention. National Diabetes Fact Sheet: National Estimates and General Information on Diabetes and Prediabetes in the United States, 2011. Department of Health and Human Services. Atlanta, GA, USA. 2011. Available at http:// www.cdc.gov/diabetes/pubs/pdf/ndfs_2011.pdf. Accessed March 01, 2012.

8. Tabak AG, Herder C, Rathmann W, Brunner EJ, Kivimaki M. Prediabetes: a high-risk state for diabetes development. Lancet. 2012; 379(9833):2279-2290.

9. Arora MK, Singh UK. Molecular mechanisms in the pathogenesis of diabetic nephropathy: An update. Vascul Pharmacol. Epub January 11, 2013.

10. Campos C. Chronic hyperglycemia and glucose toxicity: pathology and clinical sequelae. Postgrad Med. 2012;124(6):90-97.

11. Nguyen DV, Shaw LC, Grant MB. Inflammation in the pathogenesis of microvascular complications in diabetes. Front Endocrinol (Lausanne). 2012;3:170

12. Rahman S, Rahman T, Ismail AA, Rashid AR. Diabetes-associated macrovasculopathy: pathophysiology and pathogenesis. Diabetes Obes Metab. 2007;9(6):767-780.

13. Mathew V, Gersh BJ, Williams BA, et al. Outcomes in patients with diabetes mellitus undergoing percutaneous coronary intervention in the current era: a report from the Prevention of REStenosis with Tranilast and its Outcomes (PRESTO) trial. Circulation. 2004;109(4):476-480.

14. Pignone M, Alberts MJ, Colwell JA, et al. Aspirin for primary prevention of cardiovascular events in people with diabetes: a position statement of the American Diabetes Association, a scientific statement of the American Heart Association, and an expert consensus document of the American College of Cardiology Foundation. Diabetes Care. 2010;33(6):1395-1402.

15. Aneja A, Tang WH, Bansilal S, Garcia MJ, Farkouh ME. Diabetic cardiomyopathy: insights into pathogenesis, diagnostic challenges, and therapeutic options. Am J Med. 2008;121(9):748-757.

16. Maisch B, Alter P, Pankuweit S. Diabetic cardiomyopathy - fact or fiction? Herz. 2011;36(2):102-115.

17. Miki T, Yuda S, Kouzu H, Miura T. Diabetic cardiomyopathy: pathophysiology and clinical features. Heart Fail Rev. Epub March 28, 2012.

18. Sharma V, McNeill JH. Diabetic cardiomyopathy: where are we 40 years later? Can J Cardiol. 2006;22(4):305-308.

19. Tarquini R, Lazzeri C, Pala L, Rotella CM, Gensini GF. The diabetic cardiomyopathy. Acta Diabetol. 2011;48(3):173-181.

20. Bloomgarden ZT. Glycemic control in diabetes: A tale of three studies. Diabetes care. 2008;31:1913-1919.

21. Kessler II. Mortality experience of diabetic patients. A twenty-six-year follow-up study. Am J Med. 1971;51(6):715-724.

22. Vihert AM, Zhdanov VS, Matova EE. Atherosclerosis of the aorta and coronary vessels of the heart in cases of various diseases. J Atheroscler Res. 1969;9(2):179-192.

23. Ledet $\mathrm{T}$. Histological and histochemical changes in the coronary arteries of old diabetic patients. Diabetologia. 1968;4(5):268-272.

24. Rubler S, Dlugash J, Yuceoglu YZ, Kumral T, Branwood AW, Grishman A. New type of cardiomyopathy associated with diabetic glomerulosclerosis. Am J Cardiol. 1972;30(6):595-602.

25. Regan TJ, Lyons MM, Ahmed SS, et al. Evidence for cardiomyopathy in familial diabetes mellitus. J Clin Invest. 1977;60(4): 884-899.
26. Fang ZY, Prins JB, Marwick TH. Diabetic cardiomyopathy: evidence, mechanisms, and therapeutic implications. Endocr Rev. 2004;25(4): 543-567.

27. Elliott P, Andersson B, Arbustini E, et al. Classification of the cardiomyopathies: a position statement from the European Society Of Cardiology Working Group on Myocardial and Pericardial Diseases. Eur Heart J. 2008;29(2):270-276.

28. Paulus WJ, Tschope C, Sanderson JE, et al. How to diagnose diastolic heart failure: a consensus statement on the diagnosis of heart failure with normal left ventricular ejection fraction by the Heart Failure and Echocardiography Associations of the European Society of Cardiology. Eur Heart J. 2007;28(20):2539-2550.

29. Mishra PK, Tyagi N, Kumar M, Tyagi SC. MicroRNAs as a therapeutic target for cardiovascular diseases. J Cell Mol Med. 2009;13(4): 778-789.

30. Tyagi AC, Sen U, Mishra PK. Synergy of microRNA and stem cell: a novel therapeutic approach for diabetes mellitus and cardiovascular diseases. Curr Diabetes Rev. 2011;7(6):367-376.

31. Mishra PK, Chavali V, Metreveli N, Tyagi SC. Ablation of MMP9 induces survival and differentiation of cardiac stem cells into cardiomyocytes in the heart of diabetics: a role of extracellular matrix. Can J Physiol Pharmacol. 2012;90(3):353-360.

32. Goodwin GW, Taylor CS, Taegtmeyer H. Regulation of energy metabolism of the heart during acute increase in heart work. $J$ Biol Chem. 1998;273(45):29530-29539.

33. Depre C, Shipley GL, Chen W, et al. Unloaded heart in vivo replicates fetal gene expression of cardiac hypertrophy. Nat Med. 1998; 4(11):1269-1275.

34. Rodrigues B, Cam MC, McNeill JH. Metabolic disturbances in diabetic cardiomyopathy. Mol Cell Biochem. 1998;180(1-2):53-57.

35. Belke DD, Larsen TS, Gibbs EM, Severson DL. Altered metabolism causes cardiac dysfunction in perfused hearts from diabetic $(\mathrm{db} / \mathrm{db})$ mice. Am J Physiol Endocrinol Metab. 2000;279(5):E1104-E1113.

36. Kim JK, Kim YJ, Fillmore JJ, et al. Prevention of fat-induced insulin resistance by salicylate. J Clin Invest. 2001;108(3):437-446.

37. Schwartzbauer G, Robbins J. The tumor suppressor gene PTEN can regulate cardiac hypertrophy and survival. J Biol Chem. 2001;276(38): 35786-35793.

38. Morisco C, Condorelli G, Trimarco V, et al. Akt mediates the crosstalk between beta-adrenergic and insulin receptors in neonatal cardiomyocytes. Circ Res. 2005;96(2):180-188.

39. O'Neill BT, Abel ED. Akt1 in the cardiovascular system: friend or foe? J Clin Invest. 2005;115(8):2059-2064.

40. Khamzina L, Veilleux A, Bergeron S, Marette A. Increased activation of the mammalian target of rapamycin pathway in liver and skeletal muscle of obese rats: possible involvement in obesity-linked insulin resistance. Endocrinology. 2005;146(3):1473-1481.

41. Manning BD. Balancing Akt with S6K: implications for both metabolic diseases and tumorigenesis. J Cell Biol. 2004;167(3):399-403.

42. Shah OJ, Wang Z, Hunter T. Inappropriate activation of the TSC/Rheb/ $\mathrm{mTOR} / \mathrm{S} 6 \mathrm{~K}$ cassette induces IRS1/2 depletion, insulin resistance, and cell survival deficiencies. Curr Biol. 2004;14(18):1650-1656.

43. Boudina S, Abel ED. Mitochondrial uncoupling: a key contributor to reduced cardiac efficiency in diabetes. Physiology (Bethesda). 2006;21:250-258.

44. Eckel J, Reinauer H. Insulin action on glucose transport in isolated cardiac myocytes: signalling pathways and diabetes-induced alterations. Biochem Soc Trans. 1990;18(6):1125-1127.

45. Liedtke AJ, DeMaison L, Eggleston AM, Cohen LM, Nellis SH. Changes in substrate metabolism and effects of excess fatty acids in reperfused myocardium. Circ Res. 1988;62(3):535-542.

46. Liu GX, Hanley PJ, Ray J, Daut J. Long-chain acyl-coenzyme A esters and fatty acids directly link metabolism to K(ATP) channels in the heart. Circ Res. 2001;88(9):918-924.

47. Abe T, Ohga Y, Tabayashi N, et al. Left ventricular diastolic dysfunction in type 2 diabetes mellitus model rats. Am J Physiol Heart Circ Physiol. 2002;282(1):H138-H148. 
48. Malhotra A, Sanghi V. Regulation of contractile proteins in diabetic heart. Cardiovasc Res. 1997;34(1):34-40.

49. Takeda N, Nakamura I, Hatanaka T, Ohkubo T, Nagano M. Myocardial mechanical and myosin isoenzyme alterations in streptozotocin-diabetic rats. Jpn Heart J. 1988;29(4):455-463.

50. Du X, Matsumura T, Edelstein D, et al. Inhibition of GAPDH activity by poly(ADP-ribose) polymerase activates three major pathways of hyperglycemic damage in endothelial cells. J Clin Invest. 2003; 112(7):1049-1057.

51. Nishikawa T, Edelstein D, Brownlee M. The missing link: a single unifying mechanism for diabetic complications. Kidney Int Suppl. 2000;77:S26-S30.

52. Nishikawa T, Edelstein D, Du XL, et al. Normalizing mitochondrial superoxide production blocks three pathways of hyperglycaemic damage. Nature. 2000;404(6779):787-790.

53. Cai L, Kang YJ. Oxidative stress and diabetic cardiomyopathy: a brief review. Cardiovasc Toxicol. 2001;1(3):181-193.

54. Farhangkhoee H, Khan ZA, Mukherjee S, et al. Heme oxygenase in diabetes-induced oxidative stress in the heart. J Mol Cell Cardiol. 2003; 35(12):1439-1448.

55. Mishra PK, Tyagi N, Sen U, Joshua IG, Tyagi SC. Synergism in hyperhomocysteinemia and diabetes: role of PPAR gamma and tempol. Cardiovasc Diabetol. 2010;9:49.

56. Mishra PK, Metreveli N, Tyagi SC. MMP-9 gene ablation and TIMP-4 mitigate PAR-1-mediated cardiomyocyte dysfunction: a plausible role of dicer and miRNA. Cell Biochem Biophys. 2010;57(2-3):67-76.

57. Barac A, Wang H, Shara NM, et al. Markers of inflammation, metabolic risk factors, and incident heart failure in American Indians: the Strong Heart Study. J Clin Hypertens (Greenwich). 2012;14(1):13-19.

58. Bradham WS, Moe G, Wendt KA, et al. TNF-alpha and myocardial matrix metalloproteinases in heart failure: relationship to $\mathrm{LV}$ remodeling. Am J Physiol Heart Circ Physiol. 2002;282(4):H1288-H1295.

59. Bradham WS, Bozkurt B, Gunasinghe H, Mann D, Spinale FG. Tumor necrosis factor-alpha and myocardial remodeling in progression of heart failure: a current perspective. Cardiovasc Res. 2002;53(4):822-830.

60. Calle MC, Fernandez ML. Inflammation and type 2 diabetes. Diabetes Metab. 2012;38(3):183-191.

61. Moschos SA, Williams AE, Perry MM, Birrell MA, Belvisi MG, Lindsay MA. Expression profiling in vivo demonstrates rapid changes in lung microRNA levels following lipopolysaccharide-induced inflammation but not in the anti-inflammatory action of glucocorticoids. $B M C$ Genomics. 2007;8:240.

62. Perry MM, Moschos SA, WilliamsAE, Shepherd NJ, Larner-Svensson HM, Lindsay MA. Rapid changes in microRNA-146a expression negatively regulate the IL-1beta-induced inflammatory response in human lung alveolar epithelial cells. J Immunol. 2008;180(8):5689-5698.

63. Roy S, Sen CK. MiRNA in innate immune responses: novel players in wound inflammation. Physiol Genomics. 2011;43(10):557-565

64. Schaefer JS, Montufar-Solis D, Vigneswaran N, Klein JR. Selective upregulation of microRNA expression in peripheral blood leukocytes in IL-10-/- mice precedes expression in the colon. $J$ Immunol. 2011;187(11):5834-5841.

65. van de Vrie M, Heymans S, Schroen B. MicroRNA involvement in immune activation during heart failure. Cardiovasc Drugs Ther. 2011;25(2):161-170.

66. Bidasee KR, Nallani K, Yu Y, et al. Chronic diabetes increases advanced glycation end products on cardiac ryanodine receptors/calcium-release channels. Diabetes. 2003;52(7):1825-1836.

67. Candido R, Forbes JM, Thomas MC, et al. A breaker of advanced glycation end products attenuates diabetes-induced myocardial structural changes. Circ Res. 2003;92(7):785-792.

68. Cooper ME. Importance of advanced glycation end products in diabetes-associated cardiovascular and renal disease. Am J Hypertens. 2004;17(12 Pt 2):31S-38S.

69. Guo M, Wu MH, Korompai F, Yuan SY. Upregulation of PKC genes and isozymes in cardiovascular tissues during early stages of experimental diabetes. Physiol Genomics. 2003;12(2):139-146.
70. Herrmann KL, McCulloch AD, Omens JH. Glycated collagen crosslinking alters cardiac mechanics in volume-overload hypertrophy. $\mathrm{Am}$ J Physiol Heart Circ Physiol. 2003;284(4):H1277-H1284.

71. Koya D, King GL. Protein kinase C activation and the development of diabetic complications. Diabetes. 1998;47(6):859-866.

72. Wakasaki H, Koya D, Schoen FJ, et al. Targeted overexpression of protein kinase $\mathrm{C}$ beta2 isoform in myocardium causes cardiomyopathy. Proc Natl Acad Sci U S A. 1997;94(17):9320-9325.

73. Karayannis G, Giamouzis G, Cokkinos DV, Skoularigis J, Triposkiadis F. Diabetic cardiovascular autonomic neuropathy: clinical implications. Expert Rev Cardiovasc Ther. 2012;10(6):747-765.

74. Lambert GW, Straznicky NE, Lambert EA, Dixon JB, Schlaich MP. Sympathetic nervous activation in obesity and the metabolic syndrome - causes, consequences and therapeutic implications. Pharmacol Ther. 2010;126(2):159-172.

75. Mishra PK, Givvimani S, Metreveli N, Tyagi SC. Attenuation of beta2-adrenergic receptors and homocysteine metabolic enzymes cause diabetic cardiomyopathy. Biochem Biophys Res Commun. 2010;401(2):175-181.

76. Mishra PK, Awe O, Metreveli N, Qipshidze N, Joshua IG, Tyagi SC. Exercise mitigates homocysteine - beta2-adrenergic receptor interactions to ameliorate contractile dysfunction in diabetes. Int J Physiol Pathophysiol Pharmacol. 2011;3(2):97-106.

77. Wang G, Zhu X, Xie W, et al. Rad as a novel regulator of excitationcontraction coupling and beta-adrenergic signaling in heart. Circ Res. 2010;106(2):317-327.

78. Fowlkes V, Clark J, Fix C, et al. Type II diabetes promotes a myofibroblast phenotype in cardiac fibroblasts. Life Sci. Epub January 16, 2013.

79. Delucchi F, Berni R, Frati C, et al. Resveratrol treatment reduces cardiac progenitor cell dysfunction and prevents morpho-functional ventricular remodeling in type-1 diabetic rats. PLoS One. 2012;7(6):e39836.

80. Zou MH, Xie Z. Regulation of interplay between autophagy and apoptosis in the diabetic heart: New role of AMPK. Autophagy. Epub February 4, 2013.

81. Marciano C, Galderisi M, Gargiulo P, et al. Effects of type 2 diabetes mellitus on coronary microvascular function and myocardial perfusion in patients without obstructive coronary artery disease. Eur J Nucl Med Mol Imaging. 2012;39(7):1199-1206.

82. Papa G, Degano C, Iurato MP, Licciardello C, Maiorana R, Finocchiaro C. Macrovascular complication phenotypes in type 2 diabetic patients. Cardiovasc Diabetol. Epub January 18, 2013.

83. Wang CC, Reusch JE. Diabetes and cardiovascular disease: changing the focus from glycemic control to improving long-term survival. $\mathrm{Am}$ $J$ Cardiol. 2012;110(Suppl 9):58B-68B.

84. Ernande L, Thibault H, Bergerot C, et al. Systolic myocardial dysfunction in patients with type 2 diabetes mellitus: identification at MR imaging with cine displacement encoding with stimulated echoes. Radiology. 2012;265(2):402-409.

85. Zhang $\mathrm{H}$, Zhang Y, Li Z, et al. Left ventricular radial systolic dysfunction in diabetic patients assessed by myocardial acceleration derived from velocity vector imaging. J Ultrasound Med. 2012;31(8):1179-1186.

86. Asrih M, Steffens S. Emerging role of epigenetics and miRNA in diabetic cardiomyopathy. Cardiovasc Pathol. 2013;22(2):117-125.

87. Boudina S, Abel ED. Diabetic cardiomyopathy, causes and effects. Rev Endocr Metab Disord. 2010;11(1):31-39.

88. Boyer JK, Thanigaraj S, Schechtman KB, Perez JE. Prevalence of ventricular diastolic dysfunction in asymptomatic, normotensive patients with diabetes mellitus. Am J Cardiol. 2004;93(7):870-875.

89. Taegtmeyer H. Cardiac metabolism as a target for the treatment of heart failure. Circulation. 2004;110(8):894-896.

90. Cosson S, Kevorkian JP. Left ventricular diastolic dysfunction: an early sign of diabetic cardiomyopathy? Diabetes Metab. 2003;29(5): 455-466.

91. Maya L, Villarreal FJ. Diagnostic approaches for diabetic cardiomyopathy and myocardial fibrosis. J Mol Cell Cardiol. 2010;48(3):524-529.

92. Murarka S, Movahed MR. Diabetic cardiomyopathy. J Card Fail. 2010;16(12):971-979. 
93. Achenbach S, Ropers D, Regenfus M, et al. Noninvasive coronary angiography by magnetic resonance imaging, electron-beam computed tomography, and multislice computed tomography. Am J Cardiol. 2001; 88(2A):70E-73E.

94. Charoenpanichkit C, Morgan TM, Hamilton CA, et al. Left ventricular hypertrophy influences cardiac prognosis in patients undergoing dobutamine cardiac stress testing. Circ Cardiovasc Imaging. 2010;3(4):392-397.

95. Gebker R, Mirelis JG, Jahnke C, et al. Influence of left ventricular hypertrophy and geometry on diagnostic accuracy of wall motion and perfusion magnetic resonance during dobutamine stress. Circ Cardiovasc Imaging. 2010;3(5):507-514.

96. Alter P, Rupp H, Rominger MB, et al. B-type natriuretic peptide and wall stress in dilated human heart. Mol Cell Biochem. 2008;314(1-2): 179-191.

97. Alter P, Rupp H, Maisch B. Assessment and relevance of ventricular wall stress in heart failure. Eur Heart J. 2008;29(18):2316.

98. Alter P, Rupp H, Rominger MB, et al. A new method to assess ventricular wall stress in patients with heart failure and its relation to heart rate variability. Int J Cardiol. 2010;139(3):301-303.

99. Gottlieb I, Macedo R, Bluemke DA, Lima JA. Magnetic resonance imaging in the evaluation of non-ischemic cardiomyopathies: current applications and future perspectives. Heart Fail Rev. 2006; 11(4):313-323.

100. Macedo R, Schmidt A, Rochitte CE, Lima JA, Bluemke DA. MRI to assess arrhythmia and cardiomyopathies. J Magn Reson Imaging. 2006;24(6):1197-1206.

101. Jones SP. A bittersweet modification: O-GlcNAc and cardiac dysfunction. Circ Res. 2005;96(9):925-926.

102. Lunde IG, Aronsen JM, Kvaloy H, et al. Cardiac O-GlcNAc signaling is increased in hypertrophy and heart failure. Physiol Genomics. 2012;44(2):162-172.

103. Zachara NE. The roles of O-linked beta-N-acetylglucosamine in cardiovascular physiology and disease. Am J Physiol Heart Circ Physiol. 2012;302(10):H1905-H1918.

104. Bartel DP. MicroRNAs: target recognition and regulatory functions. Cell. 2009;136(2):215-233.

105. Chavali V, Tyagi SC, Mishra PK. MicroRNA-133a regulates DNA methylation in diabetic cardiomyocytes. Biochem Biophys Res Commun. 2012;425(3):668-672.

106. Feng B, Chen S, George B, Feng Q, Chakrabarti S. miR133a regulates cardiomyocyte hypertrophy in diabetes. Diabetes Metab Res Rev. 2010;26(1):40-49.

107. Ajit SK. Circulating microRNAs as biomarkers, therapeutic targets, and signaling molecules. Sensors (Basel). 2012;12(3):3359-3369.

108. Dimmeler S, Zeiher AM. Circulating microRNAs: novel biomarkers for cardiovascular diseases? Eur Heart J. 2010;31(22):2705-2707.

109. Fichtlscherer S, de RS, Fox H, et al. Circulating microRNAs in patients with coronary artery disease. Circ Res. 2010;107(5):677-684.
110. Fichtlscherer S, Zeiher AM, Dimmeler S. Circulating microRNAs: biomarkers or mediators of cardiovascular diseases? Arterioscler Thromb Vasc Biol. 2011;31(11):2383-2390.

111. Li C, Pei F, Zhu X, Duan DD, Zeng C. Circulating microRNAs as novel and sensitive biomarkers of acute myocardial Infarction. Clin Biochem. 2012;45(10-11):727-732.

112. McManus DD, Ambros V. Circulating MicroRNAs in cardiovascular disease. Circulation. 2011;124(18):1908-1910.

113. Scholer N, Langer C, Kuchenbauer F. Circulating microRNAs as biomarkers - True Blood? Genome Med. 2011;3(11):72.

114. Tijsen AJ, Pinto YM, Creemers EE. Circulating microRNAs as diagnostic biomarkers for cardiovascular diseases. Am J Physiol Heart Circ Physiol. 2012;303(9):H1085-H1095.

115. van Empel VP, De Windt LJ, da Costa Martins PA. Circulating miRNAs: reflecting or affecting cardiovascular disease? Curr Hypertens Rep. 2012;14(6):498-509.

116. Weiland M, Gao XH, Zhou L, Mi QS. Small RNAs have a large impact: circulating microRNAs as biomarkers for human diseases. RNA Biol. 2012;9(6):850-859.

117. Da SD, Ausina P, Alencar EM, Coelho WS, Zancan P, Sola-Penna M. Metformin reverses hexokinase and phosphofructokinase downregulation and intracellular distribution in the heart of diabetic mice. IUBMB Life. 2012;64(9):766-774.

118. Molavi B, Rassouli N, Bagwe S, Rasouli N. A review of thiazolidinediones and metformin in the treatment of type 2 diabetes with focus on cardiovascular complications. Vasc Health Risk Manag. 2007;3(6):967-973.

119. Bellia A, Rizza S, Galli A, et al. Early vascular and metabolic effects of rosuvastatin compared with simvastatin in patients with type 2 diabetes. Atherosclerosis. 2010;210(1):199-201.

120. Lin CL, Cheng H, Tung CW, et al. Simvastatin reverses high glucoseinduced apoptosis of mesangial cells via modulation of Wnt signaling pathway. Am J Nephrol. 2008;28(2):290-297.

121. Ma T, Tien L, Fang CL, Liou YS, Jong GP. Statins and new-onset diabetes: a retrospective longitudinal cohort study. Clin Ther. 2012;34(9):1977-1983.

122. Paolisso G, Sgambato S, De RS, et al. Simvastatin reduces plasma lipid levels and improves insulin action in elderly, non-insulin dependent diabetics. Eur J Clin Pharmacol. 1991;40(1):27-31.

123. Tawfik HE, El-Remessy AB, Matragoon S, Ma G, Caldwell RB, Caldwell RW. Simvastatin improves diabetes-induced coronary endothelial dysfunction. J Pharmacol Exp Ther. 2006;319(1):386-395.

124. Wei P, Grimm PR, Settles DC, Balwanz CR, Padanilam BJ, Sansom SC. Simvastatin reverses podocyte injury but not mesangial expansion in early stage type 2 diabetes mellitus. Ren Fail. 2009;31(6):503-513.

125. Yao XM, Ye SD, Zai Z, et al. Simvastatin protects diabetic rats against kidney injury through the suppression of renal matrix metalloproteinase-9 expression. J Endocrinol Invest. 2010;33(5): 292-296.

\section{Publish your work in this journal}

Diabetes, Metabolic Syndrome and Obesity: Targets and Therapy is an international, peer-reviewed open-access journal committed to the rapid publication of the latest laboratory and clinical findings in the fields of diabetes, metabolic syndrome and obesity research. Original research, review, case reports, hypothesis formation, expert opinion and commentaries are all considered for publication. The manuscript management system is completely online and includes a very quick and fair peer-review system, which is all easy to use. Visit http://www.dovepress.com/testimonials.php to read real quotes from published authors. 